\title{
High-Purity Electrolytic Chromium
}

\author{
Discussion of an article of the same title by M. J. Ferrante et al which ap- \\ peared in the November 1960 issue of JouRnal of METals.
}

\author{
by J. J. Dale and L. H. Esmore, \\ Defence Standards Laboratories, \\ Maribyrnong, Victoria, Australia
}

Experience over several years in the production of high-purity electrolytic chromium--mainly by the sulfate catalyzed process-prompts us to offer the following comments on the paper by Ferrante et al. ${ }^{1}$

While there is no doubt that the fluoride catalyst process is more efficient than the sulfate catalyzed process, the following points detract from its usefulness for the steady and economical production of relatively large quantities of pure metal:

1) The metal produced contains more impurities, notably oxygen and tin;

2) The solution cannot be purified

3) The aluminum cathode cannot be used; hence a soluble cathode is required, and this entails much expense and inconvenience:

4) Excessive fuming and extreme corrosivity of the solution is encountered

5) Excessive roughness and tree formation is found on cathodes with runs exceeding 15 to $20 \mathrm{hr}$;

6) Difficulties are found in maintaining solution composition; and

7) Falling efficiencies are noted with prolonged use of the bath.

Until these disadvantages are overcome, the sulfate catalyst would appear to be the better of the two processes. Its chief advantages are its relative simplicity and reliability which make it possible to operate the plant unattended over weekends by providing a suitable system of controls and safety devices. We by ion exchange;

use an aluminum cathode with a hemispherical end to give uniform current distribution. The open ended cathode used by Ferrante et al. ${ }^{1}$ would tend to promote the excessive tree growth which seems to have been a feature of their experience with the sulfate catalyst. We have studied extensively the effects of process variables on efficiency and on the oxygen content of the metal obtained with this catalyst. Both temperature and bath composition need close control. A change of $5^{\circ} \mathrm{C}$ for example, can alter the oxygen content by a factor of three. Results of this work are to be published shortly.

With the fluoride catalyst, successive experimental runs in a 5 gal tank confirm Ryan's findings ${ }^{2}$ that there is a progressive drop in efficiency despite the maintenance of the bath composition. The results given in the accompanying table show that even large additions of fluoride do not restore the efficiency to its initial value. For example, in runs 4 and 10 the amount of catalyst is the same but the efficiency has dropped by one-third in the latter run. Additions of $\mathrm{HF}$ do not raise the mean $\mathrm{HF}$ content in proportion, the loss during electrolysis being large and erratic (runs 8 and 9). Raising the trivalent content by reducing anode areas did not restore high efficiency. Lower trivalent contents are effects and not causes of lower efficiency.

It would be of interest to know if other workers are able to maintain high efficiency in successive

Production of Pure Chromium Using Fluoride Catalyzed Electrolytes Successive Test Runs at $\mathbf{5 0 0}$ amp per sq ft in 5 gal Tank

\begin{tabular}{|c|c|c|c|c|c|c|c|}
\hline \multirow{2}{*}{$\begin{array}{l}\text { Run } \\
\text { No. }\end{array}$} & \multirow{2}{*}{$\underset{h r}{\operatorname{Tim}} \mathrm{e}$} & \multirow{2}{*}{$\underset{\circ C}{\operatorname{Temp}}$} & \multirow{2}{*}{$\underset{\text { Hpl }}{\text { HF Addition, }}$} & \multicolumn{3}{|c|}{ Bath Composition, $\mathbf{g p} \mathbf{1}^{*}$} & \multirow{2}{*}{$\underset{\text { pet }}{\text { Efficiency, }}$} \\
\hline & & & & $\mathrm{CrO}_{3}$ & $\mathbf{H F}$ & $\mathrm{Cr}^{+++}$ & \\
\hline 1 & 4 & 96 & $\stackrel{0}{\text { (New Bath) }}$ & 251 & 5.0 & 1.3 & 27 \\
\hline $\begin{array}{r}2 \\
3 \\
4 \\
5 \\
6 \\
7 \\
8 \\
9 \\
10\end{array}$ & $\begin{array}{l}4 \\
4 \\
4 \\
4.5 \\
4 \\
4 \\
4 \\
4 \\
4\end{array}$ & $\begin{array}{l}96 \\
96 \\
96 \\
97 \\
97 \\
98 \\
95 \\
98 \\
97\end{array}$ & $\begin{array}{l}0.23 \\
0.23 \\
0.23 \\
0.23 \\
0.26 \\
0 \\
0.93 \\
0.46 \\
0.46\end{array}$ & $\begin{array}{l}\mathbf{2 5 9} \\
259 \\
259 \\
250 \\
248 \\
253 \\
258 \\
260 \\
\mathbf{2 5 9}\end{array}$ & $\begin{array}{l}5.1 \\
4.7 \\
4.4 \\
4.0 \\
3.7 \\
3.6 \\
4.2 \\
4.3 \\
4.5\end{array}$ & $\begin{array}{l}2.3 \\
2.3 \\
2.4 \\
1.7 \\
1.7 \\
1.0 \\
1.3 \\
1.1 \\
1.0\end{array}$ & $\begin{array}{l}32 \\
34 \\
32 \\
23 \\
21 \\
14 \\
24 \\
20 \\
20\end{array}$ \\
\hline
\end{tabular}

- Figures given are averages of concentrations before and after each run. overnight runs. It seems unlikely that the loss of fluoride through spray and evaporation can explain the effects noted. There are probably other ways in which the catalyst might also become ineffective, for example through formation of unfavorable complexes such as oxyfluorides. $^{3}$ In support of this explanation there are indications from Nuclear Magnetic Resonance (which we are trying out for rapid estimation of fluorine) that the fluorine in used electrolytes exists in two different molecular species. We propose to investigate this aspect in the near future.

\section{References}

I M. J. Ferrante, P. C. Good, F. E. Block, and D. H. Yee: High-Purity Electrolytic Chromium, Journal of Metals, vol 12, no. 11,1960 , pp. $881-865$

N. Ryan: Electrodeposition of High-Purity Chromium from Electrolytes Containing Fluoride or Fluosilicate, J. Electrochem. Soc,, vol. 07, 1960, p. 397.

${ }^{3}$ N. Ryan: Private communication.

\section{REPLY}

\section{by $M$. J. Ferrante, US Bureau of Mines}

We were pleased to learn that the work of J. J. Dale and L. H. Esmore on chromic acid-fluoride electrolytes is in general agreement with our findings. Our work differs somewhat in that silicofluoride catalyzed electrolytes were used in addition to fluoride catalyzed electrolytes. Higher current efficiencies were obtained consistently with the silicofluoride catalyzed electrolytes.

In either case, our tests were confined to intervals of only 4 to $5 \mathrm{hr}$. It would be interesting to determine if the silicofluoride electrolyte would also be susceptible to aging upon prolonged use.

Although a cathode with a hemispherical end might maintain a more uniform current distribution, our problem with excessive dendrite formation occurred over the entire cathode surface rather than at the bottom. We feel this was due primarily to the high current density at which the sulfate catalyzed electrolytes were operated and might explain why Dale and Esmore did not share the same experience. 